

\title{
Intraforaminal Location of Thoracolumbar Radicular Arteries Providing an Anterior Radiculomedullary Artery Using Flat Panel Catheter Angiotomography
}

\author{
(D). Gregg, DD.E. Sorte, and (DP. Gailloud
}

\begin{abstract}
BACKGROUND AND PURPOSE: Flat panel catheter angiotomography performed during the selective injection of intersegmental arteries offers a multiplanar assessment of the intraforaminal course of the radicular arteries providing an anterior radiculomedullary artery. Injury of anterior radiculomedullary arteries during transforaminal epidural steroid injections can result in spinal cord damage. Evaluations of the intraforaminal location of these arteries have so far been limited to anteroposterior views or the examination of cadaveric material. This study documents the in vivo intraforaminal location of thoracolumbar arteries providing an anterior radiculomedullary artery with flat panel catheter angiotomography.
\end{abstract}

MATERIALS AND METHODS: Ninety-four flat panel catheter angiotomography acquisitions obtained during the selective injection of intersegmental arteries providing an anterior radiculomedullary artery were reviewed. Measurements obtained from sagittal reconstructions were converted into a scatterplot visualization. Patients' age, sex, and side and level of the injection were recorded.

RESULTS: The location of radicular arteries could be ascertained in 78 of 94 flat panel catheter angiotomography acquisitions ( 33 women and 45 men, 22-82 years of age). Fifty-three acquisitions (67.9\%) were on the left side, and 25 (32.1\%), on the right, between T2 and L3. The arteries were found in the anterosuperior quadrant of the neural foramen in 75 cases $(96.2 \%)$, in the posterosuperior quadrant in 2 cases $(2.6 \%)$, and in the anteroinferior quadrant in 1 case (1.3\%). None were located in the posteroinferior quadrant. No differences in location were observed with age, sex, side of injection, or vertebral level.

CONCLUSIONS: Avoiding needle placement in the superior half of the neural foramen, specifically the anterosuperior quadrant, can reduce the risk of spinal cord injury during transforaminal epidural steroid injection.

ABBREVIATIONS: ARMA = anterior radiculomedullary artery; FPCA = flat panel catheter angiotomography; ISA = intersegmental arteries; $\mathrm{NF}=$ neural foramen; TFESI $=$ transforaminal epidural steroid injection

$\mathbf{F}$ at panel catheter angiotomography (FPCA) is a recently developed angiographic technique in which rotational datasets are used to generate high-resolution multiplanar reconstructions. FPCA performed during the injection of the thoracolumbar intersegmental arteries (ISA) allows documenting with precision

Received September 1, 2016; accepted after revision December 12.

From the Division of Interventional Neuroradiology (L.G., D.E.S., P.G.), and Department of Art as Applied to Medicine (L.G.), The Johns Hopkins University School of Medicine, Baltimore, Maryland.

This work was supported by a Siemens Medical Research Grant (P.G.) paid to the institution.

Paper previously presented, in part, at: Annual Meeting of the American Society of Neuroradiology and the Foundation of the ASNR Symposium, May 21-26, 2016; Washington, DC.

Please address correspondence to Philippe Gailloud, MD, Division of Interventional Neuroradiology, The Johns Hopkins Hospital, 1800 Orleans St, Bloomberg Building, Room 7218, Baltimore, MD 21287; e-mail: phg@jhmi.edu; @JohnsHopkinsINR

$\checkmark$ Indicates article with supplemental on-line video.

http://dx.doi.org/10.3174/ajnr.A5104 the intraforaminal course of radicular branches providing an anterior radiculomedullary artery (ARMA). The location of these vessels within the neural foramen (NF) is relevant to needle placement during transforaminal epidural steroid injection (TFESI), a commonly performed image-guided procedure consisting of the injection of corticosteroids at the NF. Inadvertent injection or injury of branches contributing to the supply of the anterior spinal artery during TFESI can result in spinal cord damage ${ }^{1}$ and can lead to paralysis and death. ${ }^{2,3}$ Although several cases of paralysis after TFESI have now been published, ${ }^{3,4}$ such complications are likely under-reported. ${ }^{1,5}$

Targeting the "safe triangle," an area located between the pedicle and the nerve root, has been recommended to avoid nerve injury during needle placement (Fig 1). ${ }^{6}$ However, this approach does not take into account the position of branches providing an ARMA. Evaluations of the intraforaminal location of these arteries critical to the spinal cord vascularization have so far been limited to anteroposterior views only ${ }^{7}$ or to the examination of ca- 


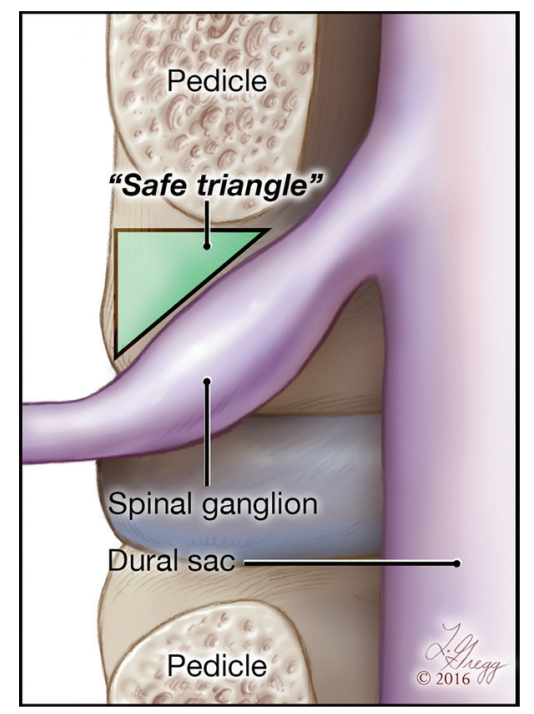

FIG 1. Illustration of the safe triangle for needle placement during the subpedicular TFESI approach. The safe triangle sides are defined in the anteroposterior projection as the inferior edge of the corresponding pedicle, the superior edge of the nerve, and the lateral margin of the neural foramen. Copyright 2016 Lydia Gregg.

daveric material. ${ }^{8,9}$ The purpose of this study was to document with precision the intraforaminal course of branches providing a thoracolumbar ARMA by using FPCA.

\section{MATERIALS AND METHODS}

FPCA studies performed during routine spinal angiography between November 2009 and September 2015 were collected retrospectively from an institutional review board-approved clinical data base. Additional approval for publication was granted. Ninety-four datasets obtained during the selective injection of the thoracolumbar ISAs providing an ARMA were reviewed. Acquisitions documenting a radicular branch and the ARMA course within the NF were included, while those with pathologies that obscured or distorted the vessel of interest were excluded. The patient's age, sex, and side and level of injection were recorded.

Datasets generated by a 20 -second nonsubtracted rotational acquisition (DynaCT, Artis Zee; Siemens, Erlangen, Germany) were reconstructed on a dedicated workstation $\left(0.1^{3}\right.$ - to $0.4^{3}-\mathrm{mm}$ voxel size, depending on the size of the FOV selected for reconstruction) and were studied with MIP rendering. Measurements were obtained by using commercially available software (OsiriX 64-bit Imaging Software; http://www.osirix-viewer.com). In a sagittal view of the injected ISA, the working projection was adjusted medially to follow the radicular artery and/or ARMA until the osseous borders of the NF were in view (On-line Video) (Fig 2). Measurements included the NF height, defined as the longest distance between the superior and inferior osseous NF borders (Fig $2 C, \mathrm{~B}_{\text {to }} \mathrm{B}^{\prime}$ ), and the NF width, measured perpendicular to and at the midpoint of the height line (Fig $2 C, \mathrm{C}$ to $\mathrm{C}^{\prime}$ ). The NF was then divided into quadrants based on the divisions created by the height and width measurement lines (Fig 2C). When osteophytes were present, the NF width was measured from the estimated original NF boundaries.

The intraforaminal location of branches providing an ARMA was evaluated by measuring the distance from the cen- ter of the artery to the inferior edge of the corresponding pedicle (Fig $2 C, \mathrm{D})$, the posterior edge of the vertebral body (Fig $2 C$, E), the horizontal NF division line (Fig $2 C, \mathrm{~F}$ ), and the vertical NF division line (Fig 2C, G). These data were used to generate a scatterplot representation. The NF height measurement was used to normalize the measurement data, thus providing a comparable point of reference for ARMAs located in NFs of various sizes.

\section{RESULTS}

The intraforaminal location of branches providing an ARMA could be ascertained in 78 of the 94 reviewed FPCA acquisitions (83.0\%), including 33 women (42.3\%) and 45 men (57.7\%) with an average age of 53 years (range, 22-82 years). Precise analysis of the ARMA course was prevented by the presence of a vascular malformation ( 2 cases), technical artifacts ( 4 cases), anatomic distortion by a tumor or prior surgery ( 4 cases), or incomplete documentation of the NF (6 cases).

Of the 78 FPCA acquisitions included in the study, 53 (67.9\%) were on the left side and $25(32.1 \%)$ were on the right. Acquisitions included vertebral levels extending from T2 to L3 (Table 1). The branches providing an ARMA were found in the anterosuperior quadrant of the NF in 75 cases $(96.2 \%)$, in the posterosuperior quadrant in 2 cases $(2.6 \%)$, and in the anteroinferior quadrant in 1 case (1.3\%) (Fig 3). Branches providing an ARMA were not found in the posteroinferior quadrant.

Most arteries providing an ARMA were close to the bone near the subpedicular notch, at the inferior border of the junction of the pedicle and the vertebral body. The center point of the arteries in 51 cases $(65.4 \%)$ was located $\leq 2 \mathrm{~mm}$ from the osseous borders of the anterosuperior quadrant of the NF.

The scatterplot of the raw data (Fig $3 A$ ) was comparable with that of the normalized data (Fig 3B), both of which documented a close association of branches providing an ARMA with the anterosuperior quadrant of the NF near the junction of the pedicle and the vertebral body.

The mean caliber of arteries providing an ARMA was $1 \mathrm{~mm}$ (range, $0.6-1.7 \mathrm{~mm}$ ). A summary of the NF and artery caliber measurements is shown in Table 2. No differences in artery location were observed with age, sex, side of injection, or vertebral level. Illustrative cases are shown in Figs 4 and 5.

\section{DISCUSSION}

\section{Methodologic Considerations}

To assess the location of the branches providing an ARMA in a clinically relevant manner, our measurements were performed in a sagittal reconstruction of the FPCA datasets matching the fluoroscopic landmarks used during TFESI (ie, a lateral projection perpendicular to the entrance of the NF). ${ }^{10}$ The vessel measured can be considered as either a radicular artery or an ARMA because the exact point of transition from one to the other remains difficult to assess by imaging and nomenclatures show slight variations. ${ }^{11,12}$ All the branches investigated for this study continued intradurally as contributors to the anterior spinal arterial axis.

The NF variability in size between patients and vertebral levels was accounted for by adopting the NF height as the normalization

AJNR Am J Neuroradiol 38:1054-60 May 2017 www.ajnr.org 

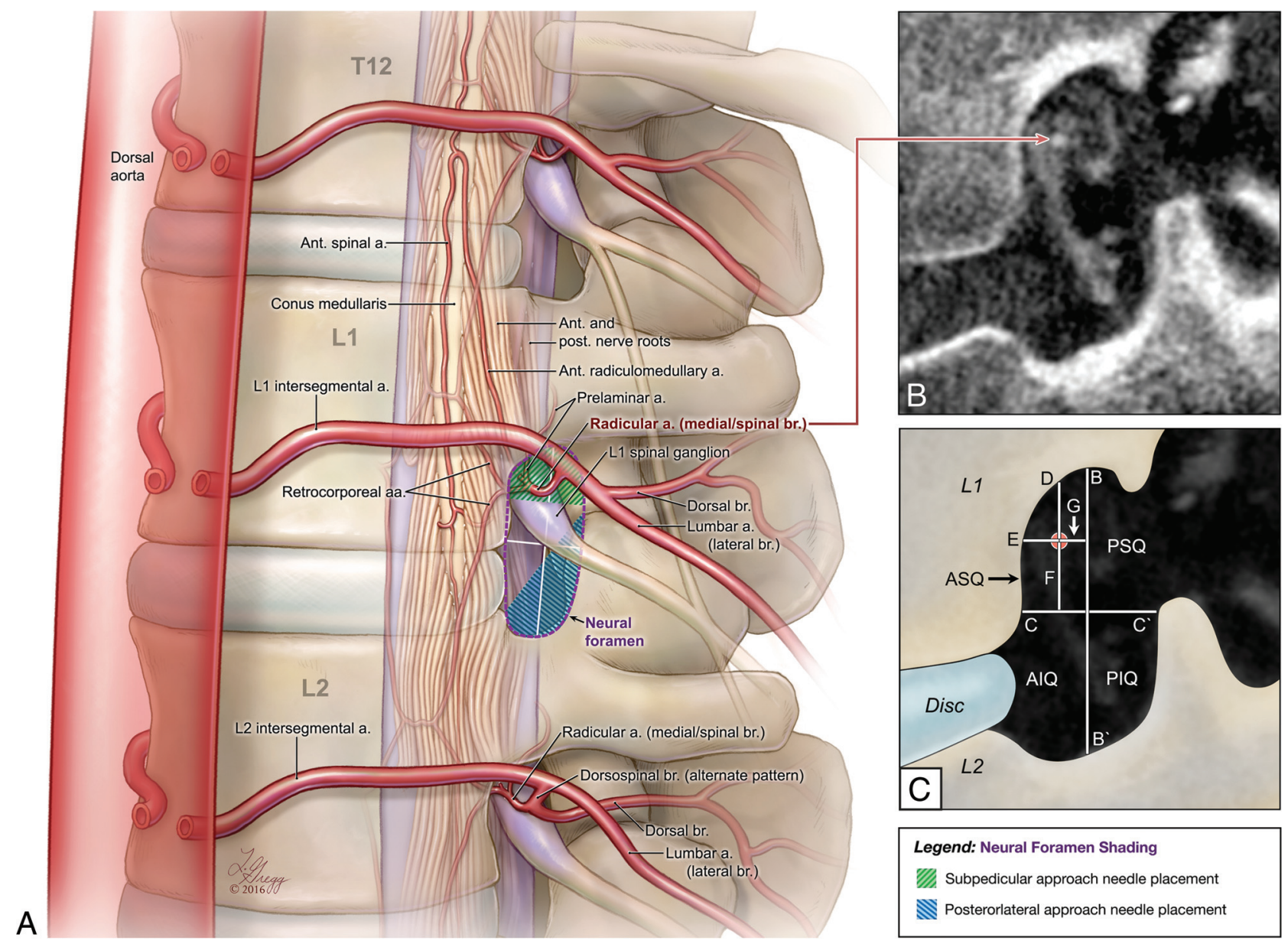

Legend: Neural Foramen Shading
Uh Subpedicular approach needle placement
Posterorlateral approach needle placement

FIG 2. Depiction of the arterial anatomy of the NF showing the measurements used in this study. A, Illustration of ISA anatomy including the principal supply to the thoracolumbar spinal cord from an anterior oblique view. The ISA originates from the aorta and divides into medial, dorsal, and lateral branches. A complete spinal branch is shown entering the NF at the left L1 vertebral level and providing a retrocorporeal artery, a prelaminar artery, and a radicular artery; the latter crosses the dura to continue as an ARMA and anastomoses with the anterior spinal artery. The shaded regions and quadrant grids depicted at the L1 NF clarify the working projection and measurement definitions depicted in $B$ and C. B, FPCA, left L1 ISA injection, sagittal reconstruction (thickness $=0.2 \mathrm{~mm}$ ) demonstrates the working projection used to take measurements. The image documents the location of an ARMA within the NF (red arrow) in a 59-year-old women investigated for acute onset paraplegia. Spinal angiography and FPCA revealed severe stenosis of the left proximal L1 ISA, resulting in an episode of spinal cord ischemia. Measurements were performed with the anterior surface to the left side. $C$, Measurements included the NF height ( $B$ to $\left.B^{\prime}\right)$, which was defined as the long axis from the posterior edge of the vertebral pedicle to the superior edge of the pedicle below. The NF was divided into quadrants by measuring the width $\left(C\right.$ to $\left.C^{\prime}\right)$ at the midpoint of the height. The ARMA location was evaluated by measuring the distance from the center of the artery to the superior (D) and anterior (E) walls of the NF and the vertical (F) and horizontal (G) distances to the quadrant divisions. ASQ indicates anterosuperior quadrant; PSQ, posterosuperior quadrant; PIQ, posteroinferior quadrant; AIQ, anteroinferior quadrant. Copyright 2016 Lydia Gregg.

Table 1: Vertebral level and side of included FPCA acquisitions documenting a radicular branch and the ARMA course within the NF

\begin{tabular}{|c|c|c|c|c|c|c|}
\hline Vertebral Level & L Side (No.) & L Side & R Side (No.) & R Side & L and R Sides, Total (No.) & $\mathrm{L}$ and $\mathrm{R}$ Sides, Total \\
\hline $\mathrm{T} 2$ & 1 & $1.3 \%$ & - & - & 1 & $1.3 \%$ \\
\hline T3 & - & - & - & - & - & - \\
\hline T4 & - & - & 1 & $1.3 \%$ & 1 & $1.3 \%$ \\
\hline T5 & 1 & $1.3 \%$ & 1 & $1.3 \%$ & 2 & $2.6 \%$ \\
\hline T6 & - & - & - & - & - & - \\
\hline 77 & 4 & $5.1 \%$ & - & - & 4 & $5.1 \%$ \\
\hline T8 & 5 & $6.4 \%$ & 3 & $3.8 \%$ & 8 & $10.3 \%$ \\
\hline T9 & 10 & $12.8 \%$ & 5 & $6.4 \%$ & 15 & $19.2 \%$ \\
\hline T10 & 2 & $2.6 \%$ & 5 & $6.4 \%$ & 7 & $9.0 \%$ \\
\hline T11 & 6 & $7.7 \%$ & 1 & $1.3 \%$ & 7 & $9.0 \%$ \\
\hline $\mathrm{T} 12$ & 7 & $9.0 \%$ & 3 & $3.8 \%$ & 10 & $12.8 \%$ \\
\hline L1 & 14 & $17.9 \%$ & 5 & $6.4 \%$ & 19 & $24.4 \%$ \\
\hline L2 & 2 & $2.6 \%$ & 1 & $1.3 \%$ & 3 & $3.8 \%$ \\
\hline L3 & 1 & $1.3 \%$ & - & - & 1 & $1.3 \%$ \\
\hline Total & 53 & $67.9 \%$ & 25 & $32.1 \%$ & 78 & $100.0 \%$ \\
\hline
\end{tabular}

Note:- L indicates left; R, right. 
Raw measurements in $\mathrm{mm}$

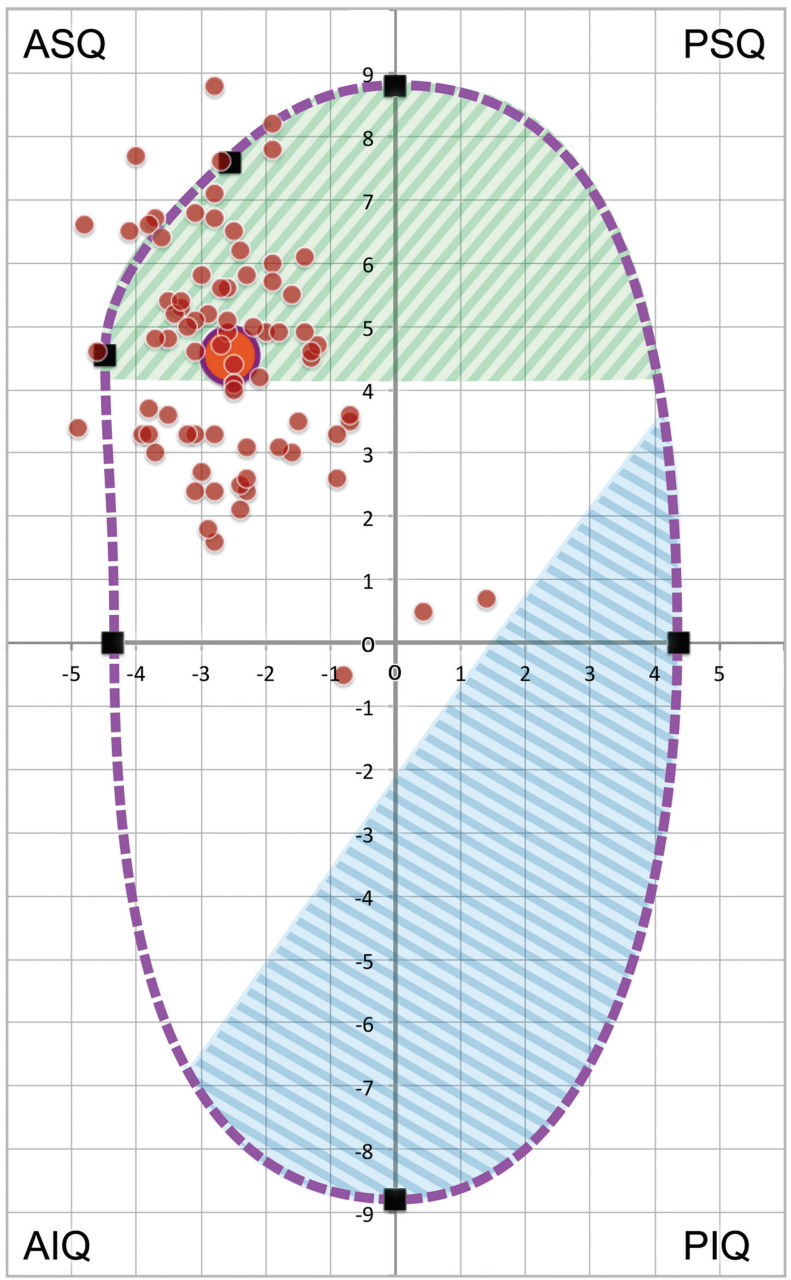

A
Normalized measurements

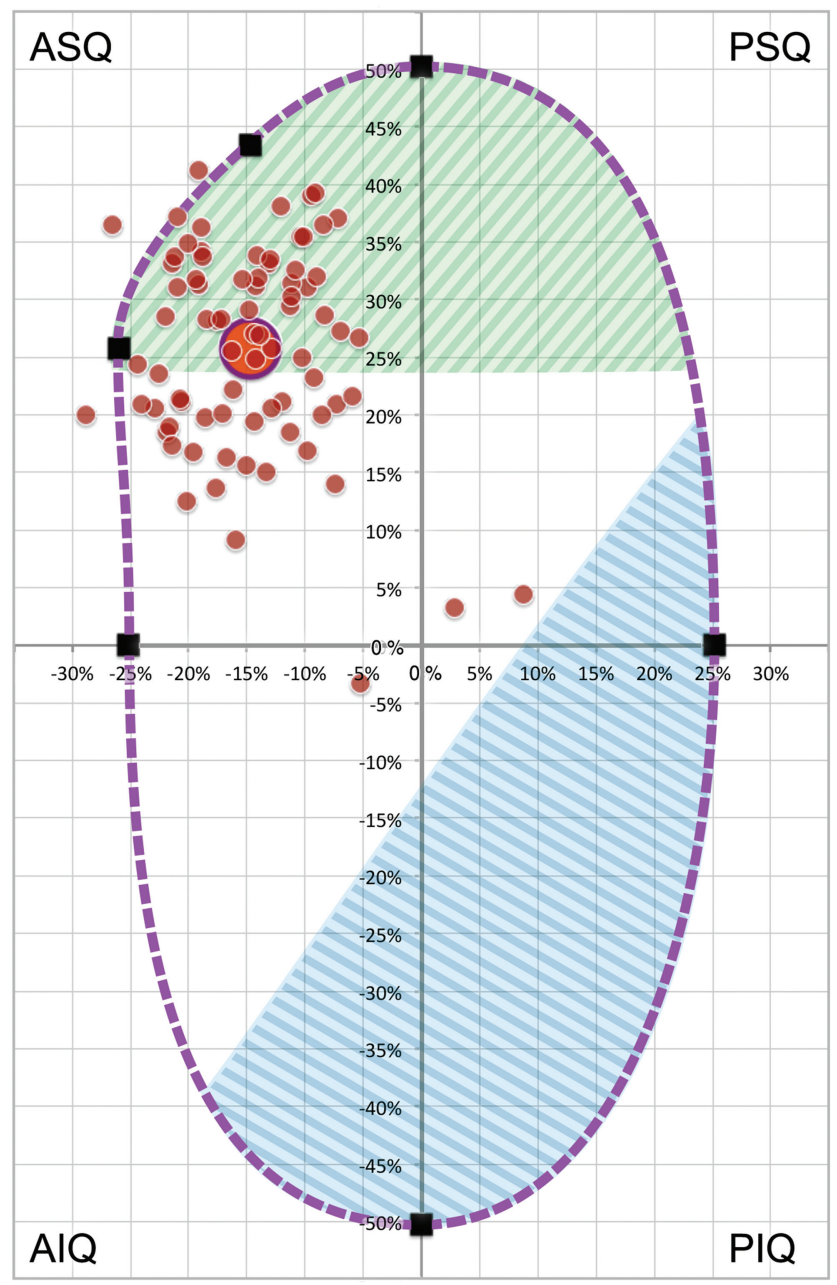

$\mathrm{B}$

\section{Legend \\ Mean neural foramen (NF) border}

Shaded regions:
Subpedicular approach needle placement
Mean artery position $=$ Estimated NF shape

Posterorlateral approach needle placement

FIG 3. Scatterplots visualizing the location within the NF of arteries that provide a thoracolumbar ARMA. A, Raw measurements in millimeters. Zero values for the $x$ - and $y$-axes represent the approximate center of the neural foramina in 78 patients. $B$, Normalized measurements, shown as a percentage of the height of the NF (NF height $=100 \%$ ) to compare the relative location of the artery within the foramina of different sizes (Measurements / NF Height $\times 100=$ Percentage NF Height) in 78 patients.

Table 2: NF and radicular branches providing ARMA lumen diameter measurements ${ }^{\mathrm{a}}$

\begin{tabular}{lclccc}
\hline Vertebral Level & No. & Measurement & Mean & Range & SD \\
\hline Thoracic ARMAs & 55 & NF height & 16.2 & $9.7-21.2$ & 2.4 \\
& & NF width & 8.0 & $5.4-12.7$ & 1.8 \\
& & ARMA diameter & 1.0 & $0.6-1.4$ & 0.2 \\
Lumbar ARMAs & 23 & NF height & 20.6 & $14.8-25$ & 2.3 \\
& & NF width & 10.3 & $8.1-13.6$ & 1.4 \\
& & ARMA diameter & 1.1 & $0.7-1.7$ & 0.3 \\
All ARMAs & \multirow{2}{*}{78} & NF height & 17.5 & $9.7-25$ & 3.1 \\
& & NF width & 8.7 & $5.4-13.6$ & 2.0 \\
& & ARMA diameter & 1.0 & $0.6-1.7$ & 0.2 \\
\hline
\end{tabular}

${ }^{\mathrm{a}}$ Data are in millimeters.

standard, considering, in particular, the relative paucity of osteophytes that form on the superior and inferior borders of the vertebral pedicles. ${ }^{13}$ No major differences in artery locations were noted between the raw measurement data and the normalized data (Fig 3).

\section{Intraforaminal Location of Branches Providing an ARMA}

The ISA consists of an aortic stem that divides into medial (or spinal), dorsal, and lateral branches; depending on the level considered, the lateral branch takes the name of posterior intercostal, subcostal, or lumbar artery (Fig $2 A$ ). The medial branch, when complete, enters the neural foramen and provides the retrocorporeal and prelaminar arteries, which contribute to the vertebral vascularization and the radicular artery. ${ }^{14} \mathrm{~A}$ radicular artery that supplies the spinal cord crosses the dura to continue as an anterior or posterior radiculomedullary artery or both, which, respectively, contribute to the anterior or posterior spinal arterial chains. Supply to the anterior thoracolumbar spinal cord is typi- 

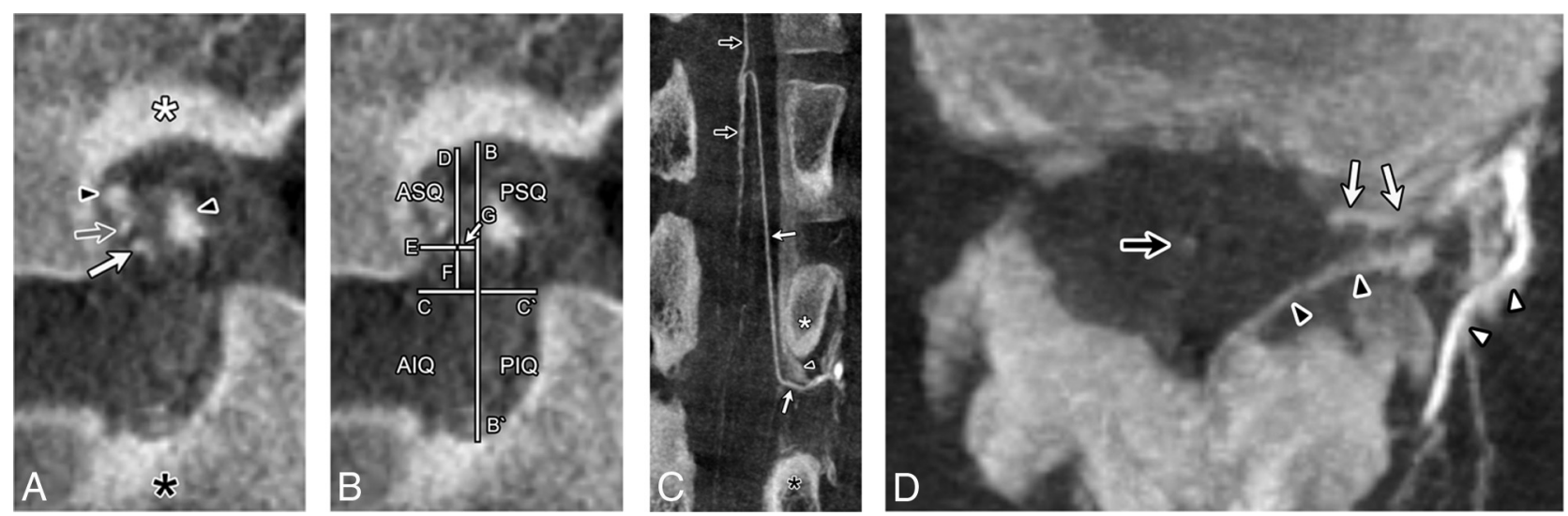

FIG 4. FPCA, left L2 ISA injection. This case illustrates the intraforaminal course of an ARMA in a 42-year-old woman investigated for progressive myelopathy. Spinal angiography and FPCA findings were unremarkable. A, Sagittal MIP reconstruction (thickness $=0.2 \mathrm{~mm}$ ) documents the location of an ARMA (white arrow) within the NF. The retrocorporeal artery (gray arrow), L2 (white asterisk) and L3 pedicles (black asterisk), and portions of the internal vertebral venous plexus (black arrowheads) are also visible. $B$, The same sagittal MIP reconstruction with graphics indicates recorded measurements, including the NF height ( $B$ to $\left.B^{\prime}\right)$, NF width ( $C$ to $C^{\prime}$ ), distance of the ARMA to the inferior border of the $L 2$ pedicle (D), the posterior wall of the $L 2$ vertebral body $(E)$, and the vertical $(F)$ and horizontal $(G)$ distances to the quadrant divisions. $C$, Coronal-oblique MIP reconstruction (thickness $=1.7 \mathrm{~mm}$ ) documents the same ARMA (white arrows) within the NF and its anastomosis with the anterior spinal artery (black arrows). The L2 (white asterisk) and L3 pedicles (black asterisk) and a portion of the internal vertebral venous plexus (black arrowhead) are also visible. D, Axial MIP reconstruction (thickness $=9.3 \mathrm{~mm}$ ) documents the same L2 ARMA (white arrows), the anterior spinal artery (black arrow), portions of the internal vertebral venous plexus (black arrowheads), and the dorsal branch of the L2 ISA (white arrowheads).
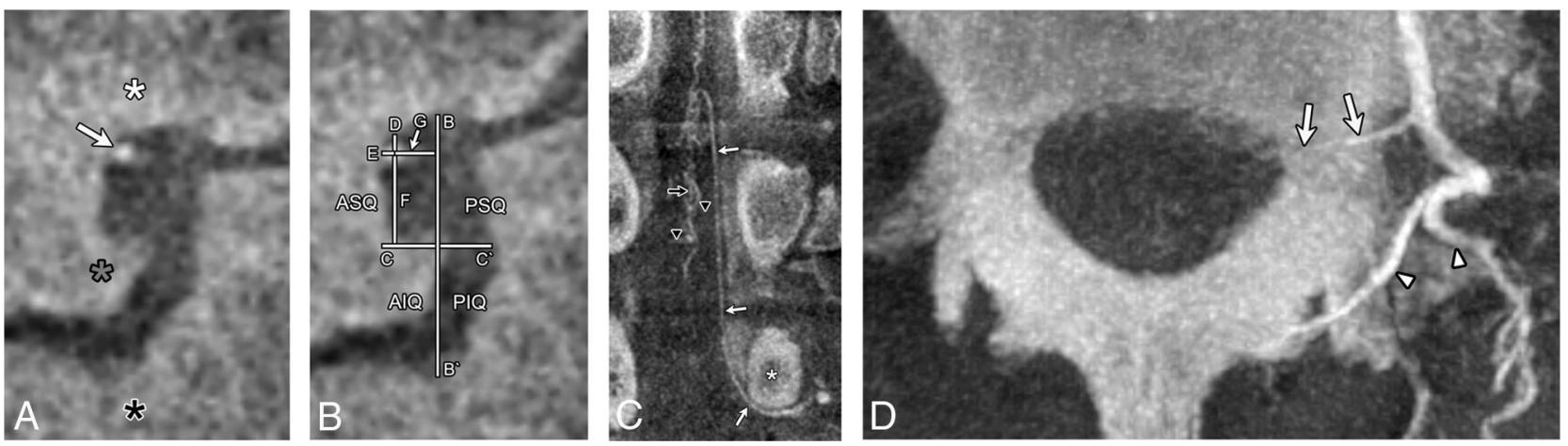

FIG 5. FPCA, left L1 ISA injection, in a 77-year-old man with severe spinal canal stenosis investigated for myelopathy. Spinal angiography and FPCA findings were normal. This case illustrates how NF width estimates were derived from abnormal foramina. A, Sagittal MIP reconstruction (thickness $=0.2 \mathrm{~mm}$ ) documents the location of a branch providing an ARMA (white arrow) within the NF. An osteophyte (gray asterisk) on the L1 vertebral body distorts the width of the NF between the L1 (white asterisk) and L2 pedicles (black asterisk), while the NF height appears unaffected. $B$, The same sagittal MIP reconstruction with graphics indicating recorded measurements includes the following: the NF height (B to $\left.B^{\prime}\right)$, estimated NF width (C to $C^{\prime}$ ), distance of the artery to the inferior border of the Ll pedicle (D), the estimated posterior wall of the L1 vertebral body $(\mathrm{E})$, and the vertical $(\mathrm{F})$ and horizontal $(\mathrm{G})$ distances to the quadrant divisions. $C$, Coronal-oblique MIP reconstruction (thickness $=1.8 \mathrm{~mm}$ ) documents the same branch providing an ARMA (white arrows) within the NF and its anastomoses with the anterior spinal artery (black arrow). The L1 (white asterisk) pedicle and a dilated anterior median spinal vein (black arrowheads) are also visible. D, Axial MIP reconstruction (thickness $=9.0 \mathrm{~mm}$ ) documents the same branch providing an ARMA (white arrows) and dorsal branches of the L1 ISA (white arrowheads).

cally limited to a dominant thoracolumbar ARMA, the artery of Adamkiewicz, and a smaller upper thoracic ARMA, the artery of von Haller. ${ }^{15}$ Reports of paralysis resulting from vascular injuries during TFESI spurred previous studies on the location of these vessels within the NF. The investigation of Murthy et al, ${ }^{7}$ based on anteroposterior views only, concluded that the radicular segment most often crosses the superior aspect of the NF. Two cadaveric studies reported that branches providing an ARMA are generally located anterosuperior to the dorsal nerve root within the NF. ${ }^{8,9}$ Our multiplanar analysis of high-resolution angiographic datasets acquired during routine clinical practice confirms and extends these observations by plotting the precise distribution of branches providing an ARMA within the NF (Fig 3).

The caliber of radicular branches that provide an ARMA mea- sured in our study (average, $1.0 \mathrm{~mm}$; range, $0.6-1.7 \mathrm{~mm}$ ) was comparable with that in prior investigations, which have reported diameters ranging from 1.2 to $2.5 \mathrm{~mm}$ (average, $1.9 \mathrm{~mm})^{8}$ and from 0.8 to $1.9 \mathrm{~mm}$ (average, $1.2 \mathrm{~mm})^{9}$ (measurements obtained in anatomic specimens, including the vessel wall thickness).

\section{Clinical Implications for Arterial Injury}

Despite being associated with severe complications related to the intraforaminal location of radicular branches that provide an ARMA, ${ }^{3}$ TFESI has seen its rate of use steadily increase due to its purported superiority over alternative techniques, such as the caudal or interlaminar approaches. ${ }^{1}$ Spinal cord ischemia and stroke occurring during TFESI may result from arterial embolization with air or particulate steroids ${ }^{1}$ or from direct vessel 
injuries such as spasm, laceration, and dissection. ${ }^{16}$ The close association between branches providing an ARMA and the subpedicular notch documented in our study emphasizes the danger in making contact between the needle and the pedicle, as is typical with the subpedicular approach. ${ }^{1}$ Multiple attempts at repositioning the needle tip, as reported in several cases of paralysis, ${ }^{16,17}$ likely increase the risk of vessel damage.

\section{The Role of Particulate Steroids}

All 19 observations of paralysis reported so far have involved the injection of particulate steroids during TFESI. ${ }^{3,4}$ With particle sizes ranging from 1 to $100 \mu \mathrm{m}$, an intra-arterial injection could result in the embolization of spinal arterioles. ${ }^{18}$ Direct arterial injection of particulate steroids has caused permanent neurologic damage in animal models, while nonparticulate steroids such as dexamethasone ${ }^{19,20}$ and prednisolone $e^{20}$ produced no injuries. Although it has been suggested that particulate steroids are more effective than nonparticulate steroids, no significant difference in efficacy after lumbar TFESI has been reported. ${ }^{21,22}$ It is possible that the small number of reported complications and the widespread use of particulate steroids ${ }^{21}$ falsely suggest a causative relationship between particulate injectate and the risk of paralysis. Nonetheless, dexamethasone became the recommended injectate for TFESI in $2010 .^{21}$

\section{Posterolateral Approach}

Positioning the needle in the region of the NF known as the Kambin triangle ${ }^{23}$ has been recommended as a safer alternative to the subpedicular approach. ${ }^{1}$ In this posterior triangle or posterolateral approach, the targeted area is defined by the posterior margin of the exiting nerve root, the endplate of the caudal vertebral level, and the articular facet of the cranial vertebral level. ${ }^{23}$ This approach was proposed for arthroscopic discectomy, ${ }^{23}$ which requires the transforaminal placement of large-caliber instrumentation. ${ }^{1}$ TFESI via the posterolateral approach has shown pain reduction scores similar to the those with the subpedicular approach, ${ }^{24}$ while decreasing both the amount of periprocedural pain and the risk of nerve damage. ${ }^{25}$ Considering that the posterolateral approach targets the posteroinferior quadrant of the NF, where branches providing an ARMA are least likely encountered, and that it has not yet been associated with reports of paralysis suggests that it should be the preferred technique for TFESI. ${ }^{1}$

\section{Misconceptions Regarding Spinal Vascular Anatomy and the "Safe Triangle"}

Several misconceptions have led to a slow rejection of the subpedicular approach, ${ }^{1}$ notably the incorrect notions that the "safe triangle" helps prevent vascular injuries in addition to nerve damage and that arterial opacification is reliably detected during contrast injections performed before steroid instillation. ${ }^{1}$ Intra-arterial needle tip placement during TFESI can, in fact, not be excluded with certainty by using intermittent fluoroscopy, ${ }^{26,27}$ aspiration, ${ }^{27-30}$ contrast injection, ${ }^{1}$ or even digital subtraction angiography. ${ }^{1,31}$ In addition, none of these imaging methods would help avoid other injury mechanisms such as arterial transection or dissection. A limited understanding of spinal vascular anatomy, which is often overlooked or misrepresented, ${ }^{10}$ also plays a role.

Simon et $\mathrm{al}^{32}$ reported the presence of arteries both in the subpedicular region and the posterolateral triangle on contrastenhanced CT scans, but the vessels observed with that technique cannot be clearly identified as branches providing an ARMA or osteomeningeal branches or even venous structures such as radiculomedullary veins or the emissary veins linking the internal and external venous plexuses at each vertebral level. Figures 4 and 5 illustrate the advantage offered by a high-resolution imaging technique to reliably distinguish such minute vascular elements on the basis of their morphology (ie, termination of the radiculomedullary veins into the epidural plexus) or opacification pattern. A similar lack of specificity is found in a report of apparent retrograde flow into a T6 spinal artery noted during a posterolateral approach, ${ }^{33}$ which prompted Simon et al ${ }^{32}$ to suggest that the injection of any artery near the NF carries potential clinical consequences. However, the images documenting that observation only show the opacification of the external epidural venous plexus with retrograde filling of a basivertebral and intraosseous venous system. An analysis of reports of paralysis following TFESI in which the needle position was mentioned shows that spinal cord damage only occurred in association with the subpedicular approach, ${ }^{3}$ a fact weakening the role of retrograde injections and the notion that any artery in the vicinity of the NF has clinical consequences comparable with those supplying ARMAs when performing TFESI.

\section{Study Limitations}

The goal of our study was to describe the typical location of radicular branches providing an ARMA in the NF based on FPCA datasets acquired in patients principally investigated for myelopathy. This patient group may have a lower incidence of degenerative osteodiscal pathology than the population typically treated with TFESI, leading to a more stable distribution of contributors of ARMAs within the NF.

\section{CONCLUSIONS}

Thoracolumbar radicular branches providing an ARMA were located in the anterosuperior quadrant of the NF in 75 of 78 patients (96.2\%), suggesting that needle placement in that area should be avoided during TFESI. Unlike the subpedicular approach, the posterolateral approach allows placing the needle tip away from the documented position of ARMA contributors within the NF, reducing the risk of intra-arterial injection or injury to the spinal vascularization.

Disclosures: Lydia Gregg_UNRELATED: Board Membership: Association of Medical Illustrators Board of Governors. Danielle Eckart Sorte-UNRELATED: Travel/Accommodations/Meeting Expenses Unrelated to Activities Listed: Stryker Neurovascular, Penumbra, Comments: Fellows courses, user courses. Philippe GailloudRELATED: Grant: Siemens, Comments: grants for the development of low-dose angiography protocols*; UNRELATED: Consultancy: Codman Neurovascular; Stock/ Stock Options: ArtVentive Medical.* *Money paid to the institution.

\section{REFERENCES}

1. Glaser SE, Shah RV. Root cause analysis of paraplegia following transforaminal epidural steroid injections: the 'unsafe' triangle. Pain Physician 2010;13:237-44 Medline 
2. Gharibo C, Koo C, Chung J, et al. Epidural steroid injections: an update on mechanisms of injury and safety. Techniques in Regional Anesthesia and Pain Management 2009;13:266-71 CrossRef

3. Atluri S, Glaser SE, Shah R, et al. Needle position analysis in cases of paralysis from transforaminal epidurals: consider alternative approaches to traditional technique. Pain Physician 2013;16:321-34 Medline

4. AbdeleRahman KT, Rakocevic G. Paraplegia following lumbosacral steroid epidural injections. J Clin Anesth 2014;26:497-99 CrossRef Medline

5. Bogduk N, Dreyfuss P, Baker R, et al. Complications of spinal diagnostic and treatment procedures. Pain Med 2008;9(suppl 1):S11-34 CrossRef

6. Bogduk N, Aprill C, Derby R. Selective nerve root blocks. In: Wilson DJ, ed. Practical Interventional Radiology of the Musculoskeletal System. London: Edward Arnold; 1995:121-32

7. Murthy NS, Maus TP, Behrns CL. Intraforaminal location of the great anterior radiculomedullary artery (artery of Adamkiewicz): a retrospective review. Pain Med 2010;11:1756-64 CrossRef Medline

8. Alleyne $\mathrm{CH}$ Jr, Cawley CM, Shengelaia GG, et al. Microsurgical anatomy of the artery of Adamkiewicz and its segmental artery. $\mathrm{J} \mathrm{Neu-}$ rosurg 1998;89:791-95 CrossRef Medline

9. Kroszczynski AC, Kohan K, Kurowski M, et al. Intraforaminal location of thoracolumbar anterior medullary arteries. Pain Med 2013; 14:808-12 CrossRef Medline

10. La Barge DV, Shah LM. Specialty Imaging: Essentials of Image-Guided Procedures_Pain Management. Salt Lake City: Amirsys; 2011

11. Djindjian R. Angiography of the Spinal Cord. Baltimore: University Park Press; 1970

12. Federative Committee on Anatomical Terminology. Terminologia Anatomica: International Anatomical Terminology. Stuttgart: Thieme; 1998

13. Rauschning W, Eysel P, Hopf C, et al. Pathoanatomy of lumbar disc degeneration and stenosis. Acta Orthop Scand Suppl 1993;64:3-12

14. Hovelacque A. Le thorax, anatomie médico-chirurgicale. Paris: Maloine; 1937

15. Gailloud P. The artery of von Haller: a constant anterior radiculomedullary artery at the upper thoracic level. Neurosurgery 2013;73: 1034-43 CrossRef Medline

16. Glaser SE, Falco F. Paraplegia following a thoracolumbar transforaminal epidural steroid injection. Pain Physician 2005;8:309-14 Medline

17. Lyders E, Morris P. A case of spinal cord infarction following lumbar transforaminal epidural steroid injection: MR imaging and angiographic findings. AJNR Am J Neuroradiol 2009;30:1691-93 CrossRef Medline

18. Thefenne L, Dubecq C, Zing E, et al. A rare case of paraplegia complicating a lumbar epidural infiltration. Ann Phys Rehabil Med 2010; 53:575-83 CrossRef Medline

19. Dawley JD, Moeller-Bertram T, Wallace MS, et al. Intra-arterial in- jection in the rat brain: evaluation of steroids used for transforaminal epidurals. Spine 2009;34:1638-43 CrossRef Medline

20. Okubadejo GO, Talcott MR, Schmidt RE, et al. Perils of intravascular methylprednisolone injection into the vertebral artery: an animal study. J Bone Joint Surg Am 2008;90:1932-38 CrossRef Medline

21. El-Yahchouchi C, Geske JR, Carter RE, et al. The noninferiority of the nonparticulate steroid dexamethasone vs the particulate steroids betamethasone and triamcinolone in lumbar transforaminal epidural steroid injections. Pain Med 2013;14:1650-57 CrossRef Medline

22. Kennedy DJ, Plastaras C, Casey E, et al. Comparative effectiveness of lumbar transforaminal epidural steroid injections with particulate versus nonparticulate corticosteroids for lumbar radicular pain due to intervertebral disc herniation: a prospective, randomized, double-blind trial. Pain Med 2014;15:548-55 CrossRef Medline

23. Kambin P, O’Brien E, Zhou L, et al. Arthroscopic microdiscectomy and selective fragmentectomy. Clin Orthop Rel Res 1998;347:150-67 Medline

24. Park KD, Lee J, Jee H, et al. Kambin triangle versus the supraneural approach for the treatment of lumbar radicular pain. Am J Phys Med Rehabil 2012;91:1039-50 CrossRef Medline

25. Lee IS, Kim SH, Lee JW, et al. Comparison of the temporary diagnostic relief of transforaminal epidural steroid injection approaches: conventional versus posterolateral technique. AJNR Am J Neuroradiol 2007;28: 204-08 Medline

26. Smuck M, Fuller BJ, Yoder B, et al. Incidence of simultaneous epidural and vascular injection during lumbosacral transforaminal epidural injections. Spine J 2007;7:79-82 CrossRef Medline

27. Furman MB, O’Brien EM, Zgleszewski TM. Incidence of intravascular penetration in transforaminal lumbosacral epidural steroid injections. Spine 2000;25:2628-32 CrossRef Medline

28. Sullivan WJ, Willick SE, Chira-Adisai W, et al. Incidence of intravascular uptake in lumbar spinal injection procedures. Spine 2000;25: 481-86 CrossRef Medline

29. Ho K. Vascular uptake of contrast despite negative aspiration in interlaminar cervical epidural injection. Pain Physician 2006;9: 267-68 Medline

30. Manchikanti L, Cash KA, Pampati V, et al. Evaluation of lumbar transforaminal epidural injections with needle placement and contrast flow patterns: a prospective, descriptive report. Pain Physician 2004;7:217-23 Medline

31. Chang CG, Candido KD, Knezevic NN. Digital subtraction angiog raphy does not reliably prevent paraplegia associated with lumbar transforaminal epidural steroid injection. Pain Physician 2012;15: 515-23 Medline

32. Simon JI, McAuliffe M, Smoger D. Location of radicular spinal arteries in the lumbar spine from analysis of $\mathrm{CT}$ angiograms of the abdomen and pelvis. Pain Med 2016;17:46-51 CrossRef Medline

33. Yin $\mathrm{W}$, Bogduk N. Retrograde filling of a thoracic spinal artery during transforaminal injection. Pain Med 2009;10:689-92 CrossRef Medline 